\title{
Marshall University
}

\section{Marshall Digital Scholar}

Biological Sciences Faculty Research

Biological Sciences

Fall 11-2009

\section{Indentation as a Technique to Assess the Mechanical Properties of Fallback Foods}

Peter W. Lucas

Paul J. Constantino

Biological Sciences, paulconstantino@gmail.com

Janine Chalk

Charles Ziscovici

Barth W. Wright

See next page for additional authors

Follow this and additional works at: http://mds.marshall.edu/bio_sciences_faculty

Part of the Biological and Physical Anthropology Commons

\section{Recommended Citation}

Lucas, Peter W.; Constantino, Paul J.; Chalk, Janine; Ziscovici, Charles; Wright, Barth W.; Fragaszy, Dorothy M.; Hill, David A.; Lee, James Jin-Wu; Chai, Herzl; Darvell, Brian W.; and Yuen, Tony D.B., "Indentation as a Technique to Assess the Mechanical Properties of Fallback Foods" (2009). Biological Sciences Faculty Research. 36.

http://mds.marshall.edu/bio_sciences_faculty/36

This Article is brought to you for free and open access by the Biological Sciences at Marshall Digital Scholar. It has been accepted for inclusion in Biological Sciences Faculty Research by an authorized administrator of Marshall Digital Scholar. For more information, please contact

zhangj@marshall.edu,martj@marshall.edu. 


\section{Authors}

Peter W. Lucas, Paul J. Constantino, Janine Chalk, Charles Ziscovici, Barth W. Wright, Dorothy M. Fragaszy, David A. Hill, James Jin-Wu Lee, Herzl Chai, Brian W. Darvell, and Tony D.B. Yuen 


\title{
Indentation as a Technique to Assess the Mechanical Properties of Fallback Foods
}

\author{
Peter W. Lucas, ${ }^{1 \star}$ Paul J. Constantino, ${ }^{1}$ Janine Chalk, ${ }^{1}$ Charles Ziscovici, ${ }^{1}$ Barth W. Wright, ${ }^{2}$ \\ Dorothy M. Fragaszy, ${ }^{3}$ David A. Hill, ${ }^{4}$ James J.-W. Lee, ${ }^{1}$ Herzl Chai, ${ }^{5}$ \\ Brian W. Darvell, ${ }^{6}$ Paul K.D. Lee, ${ }^{6}$ and Tony D.B. Yuen ${ }^{6}$ \\ ${ }^{1}$ Department of Anthropology, Center for the Advanced Study of Human Paleobiology, \\ The George Washington University, Washington, DC \\ ${ }^{2}$ Department of Anatomy, Kansas City University of Medicine and Biosciences, Kansas City, MO \\ ${ }^{3}$ Department of Psychology, University of Georgia, Athens, GA \\ ${ }^{4}$ Department of Biology and Environmental Science, School of Life Sciences, \\ University of Sussex, Falmer, Brighton, UK \\ ${ }^{5}$ School of Mechanical Engineering, Tel-Aviv University, Tel-Aviv, Israel \\ ${ }^{6}$ Dental Materials Science, University of Hong Kong, Peoples Republic of China
}

KEY WORDS hardness; elastic modulus; fallback foods; fracture mechanics; bite force

\begin{abstract}
A number of living primates feed partyear on seemingly hard food objects as a fallback. We ask here how hardness can be quantified and how this can help understand primate feeding ecology. We report a simple indentation methodology for quantifying hardness, elastic modulus, and toughness in the sense that materials scientists would define them. Suggested categories of fallback foods-nuts, seeds, and root vegetables-were tested, with accuracy checked on standard materials with known properties by the same means. Results were generally consistent, but the moduli of root vegetables were overestimated here. All these properties are important components of what fieldworkers mean by hardness and help understand how food properties influence primate behavior. Hardness sensu stricto deter-
\end{abstract}

At certain times of the year, primates switch their diets toward fallback items that are otherwise avoided. Very often, these foods are described as being hard. Perhaps the best documented examples of hard-food consumption by primates are seen among the pitheciins (Kinzey and Norconk, 1990, 1993), mangabeys (Lambert et al., 2004), capuchins (Wright, 2005), and orangutans (Vogel et al., 2008). When eaten seasonally, these foods are classifiable as fallback foods of the "filler" category, the consumption of which is inversely related to the availability of preferred foods (Marshall and Wrangham, 2007). Such foods are currently postulated to have major evolutionary consequences for the morphology of the feeding apparatus, including the evolutionarily important characteristic of molar enamel thickness (Lambert et al., 2004; Marshall and Wrangham, 2007). However, the problem in examining this suggestion by analysis and experimentation is that there are very few quantitative measurements of the physical properties of these foods. One problem is the actual definition of hardness in terms of material properties. The other is the difficulty of shaping hard food particles into specimens that comply with criteria given in the materials testing literature. For example, shaping a seed coat mines whether foods leave permanent marks on tooth tissues when they are bitten on. The force at which a food plastically deforms can be estimated from hardness and modulus. When fallback foods are bilayered, consisting of a nutritious core protected by a hard outer coat, it is possible to predict their failure force from the toughness and modulus of the outer coat, and the modulus of the enclosed core. These forces can be high and bite forces may be maximized in fallback food consumption. Expanding the context, the same equation for the failure force for a bilayered solid can be applied to teeth. This analysis predicts that blunt cusps and thick enamel will indeed help to sustain the integrity of teeth against contacts with these foods up to high loads. Am J Phys Anthropol 140:643-652, 2009. @ 2009 Wiley-Liss, Inc. into an accurate beam for three-point bending or into a double cantilever, both common methods for getting deformation and fracture properties in hard materials (and both described in Atkins and Mai, 1985), is very difficult in field conditions. When such specimens can be made, it is easy to exceed the current $100 \mathrm{~N}$ force limit in a portable tester like the Darvell tester (Darvell et al., 1996). This has led to the largest major investigation of the mechanical properties of primate foods pub-

\footnotetext{
Grant sponsor: GWU Strategic Plan for Academic Excellence. Grant sponsor: NSF HOMINID; Grant number: BCS 0725122.

*Correspondence to: Peter Lucas, Department of Anthropology, The George Washington University, 2110 G Street NW, Washington, DC 20052, USA. E-mail: peterwlucas@gmail.com
}

Received 29 September 2008; accepted 23 December 2008

DOI 10.1002/ajpa.21026

Published online in Wiley InterScience

(www.interscience.wiley.com). 
lished to date (Vogel et al., 2008) necessarily lacking data on the hardest food items. Yet these hard items may well have been crucial fallback items that, over time, have selected for dento-facial features like large jaw muscles and thickened enamel in the consuming primates.

The first issue is that of terminology. To a materials scientist, the hardness $H$ of a material is its resistance to indentation, measured as the force producing unit area of plastic deformation under the indenter (Tabor, 1951). However, this is not the definition of hardness suggested for feeding studies (Lucas et al., 2000, 2002; Vincent et al., 2002; Lucas, 2004; Vogel et al., 2008), which is the square root of the product of the elastic modulus $E$ (the stress-strain stiffness in the elastic range), and the fracture energy $R$, the energy expended required to grow a crack of unit area. This quantity, i.e., $(E R)^{0.5}$, is often called toughness $(T)$ by materials scientists, which they take to be the resistance to crack propagation (Lawn, 1993). Thus, what some people call "toughness," others refer to as "hardness." However, provided it is made clear which definition is being employed, and that the testing protocol is clear, measuring the values and demonstrating their consequences are the useful aspects of the work. The use of measuring such properties for feeding studies for estimating break forces and understanding tooth design is our main aim here.

Indentation hardness tests originally involved large areas of contact and therefore high forces. However, the tests have been progressively miniaturized; a critical advantage to this being that the size of an indentation can then be matched to the size of structures that determine the mechanical response of a material under load. Indentations involving nanometer displacements have shown that much of the fracture resistance of enamel is associated with the large strains that the organic matrix develops between individual crystallites, allowing the latter to displace easily, with the absorption of considerable energy (He and Swain, 2007). This deflection mechanism is common to bone, mollusk shell, wood, and man-made fiber composites (Fratzl, 2007). However, nanoindentation may be insufficient to initiate cracking, so information on the initiation and progress of fractures must be monitored at a larger scale. Microindentation achieves this by sinking an indenter to sub-millimeter depths from which cracks often form in brittle materials (Anstis et al., 1981). Finally, in the oldest version of the test, a macroindenter sinks millimeters into a tissue. This test offers a simpler method of obtaining toughness by placing the indenter close to a free surface to form a small fragment of material (Chai and Lawn, 2007). Its scale is also much more relevant to the gross organization of the enamel cap of a tooth (Lawn et al., 2008) with respect to fallback foods.

With any of these tests, it is possible to use depthsensing both to measure the hardness of a material during loading and the elastic modulus from the rebound of the deepest part of the indentation (Lawn and Howes, 1981). This article reports a method of obtaining indentation hardness and elastic modulus of hard foods in the field using one easy-to-operate test. We assess the accuracy of this, and demonstrate how knowledge of these values would benefit an assessment of the evolutionary influence of these mechanical properties on the primate consumer. In addition, we also indicate briefly how recent advances in fracture mechanics (Chai and Lawn,
2007) allow toughness estimates to be obtained by chipping these foods.

\section{MATERIALS AND METHODS Test apparatus}

Vickers indenters were fabricated from 6-mm diameter high-speed steel and tungsten carbide rods by grinding one end into the shape of the required square pyramid, the junction of the faces making an angle of $136^{\circ}$ at the apex. The stainless steel suffices for most foods, but chipping tests on glass required the extra hardness of tungsten carbide. The rods were held in a hard aluminum alloy block by an Allen screw. This block was tapped on the opposite face to receive the stud of either a $100 \mathrm{~N}$ or a 1,000 N miniature load cell (Sensotec, Columbus, OH) beneath the crosshead on a Darvell HKU portable mechanical tester (Darvell et al., 1996; Fig. 1). The Darvell tester is a hand-wound device that can be used in remote field situations. Its key features are its portability and reliability even in very humid environments. Crosshead movement is effected by manually turning a handle and monitored by a sector disc-encoder revolution counter (Darvell et al., 1996). To get true force vs. displacement data, the tester reads the force after every micrometer of crosshead movement. The tester is connected via a PCMCIA A-D card (model 6062E) to a laptop computer running Labview 7.1 (both National Instruments, Austin TX) and the combination thus functions as a miniature universal testing machine without the need for strict rate control.

\section{Specimens}

As standards, specimens of industrial polymers-polymethyl methacrylate, polycarbonate (Makrolon, Bayer Material Science, Leverkusen, Germany), polytetrafluoroethylene (Teflon, DuPont, Wilmington, DE), and polystyrene foam (manufacturer unknown; density $0.024 \mathrm{~g}$ $\mathrm{cm}^{-3}$ ) - were employed as standards for hardness-modulus tests. These were tested for their elastic modulus independently by a dynamic vibration excitation test (Grindosonic, Lemmens NV, Leuven, Belgium). However, given that dynamic moduli tend to be larger than static values, these estimates, and those for hardness, were supplemented with literature estimates. For chipping tests, we used sodalime glass as a standard because the properties of this ceramic are well-known (Lawn, 1993). The glass blocks were polished down to a $1 \mu \mathrm{m}$ finish with diamond paste prior to testing.

To represent fallback foods, we tested various seed shells (origins listed in Table 1), plus some seed kernels and two root vegetables from commercial suppliers. The commercially obtained specimens were tested as received. The seed shells and palm nuts were all dry, although testing of seed shells in other studies has shown little difference between wet and dry specimens for most properties (Jennings and Macmillan, 1986; Wang and Mai, 1994; Williamson and Lucas, 1995). Parts of the specimens used for testing were chosen at random. All specimens were fashioned with a flat upper surface, ensuring a specimen thickness at least 10 times the depth of the intended indentation to avoid the "anvil" effect. Seed shells were polished down with 600 grit abrasive paper prior to testing to provide a flat surface for hardness-modulus tests. For chipping, a side 

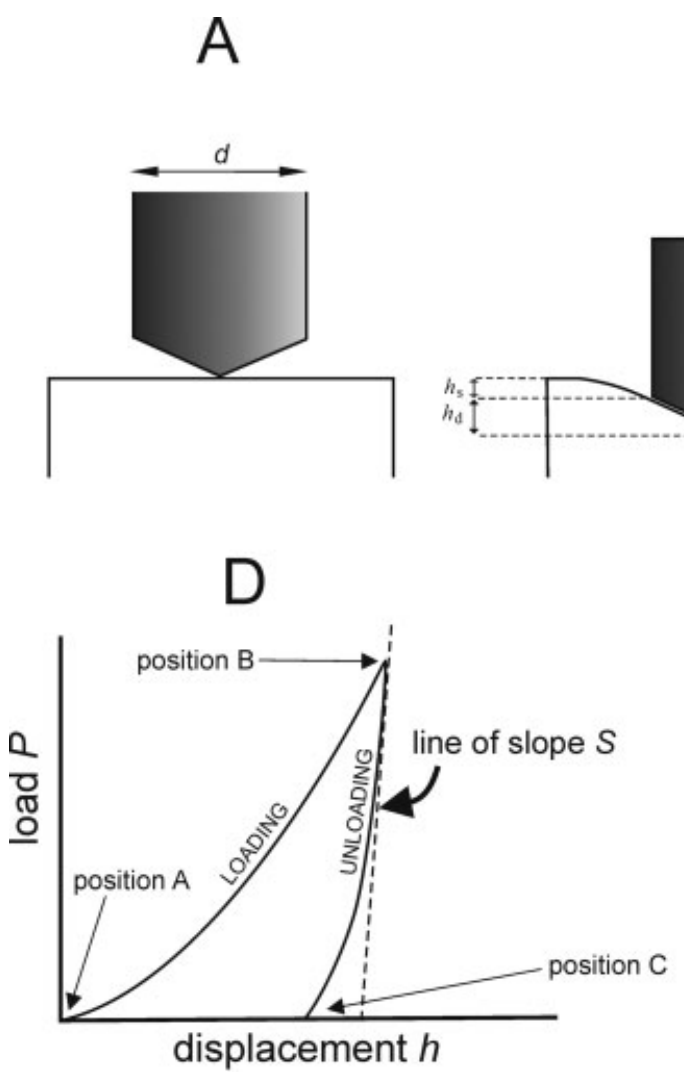
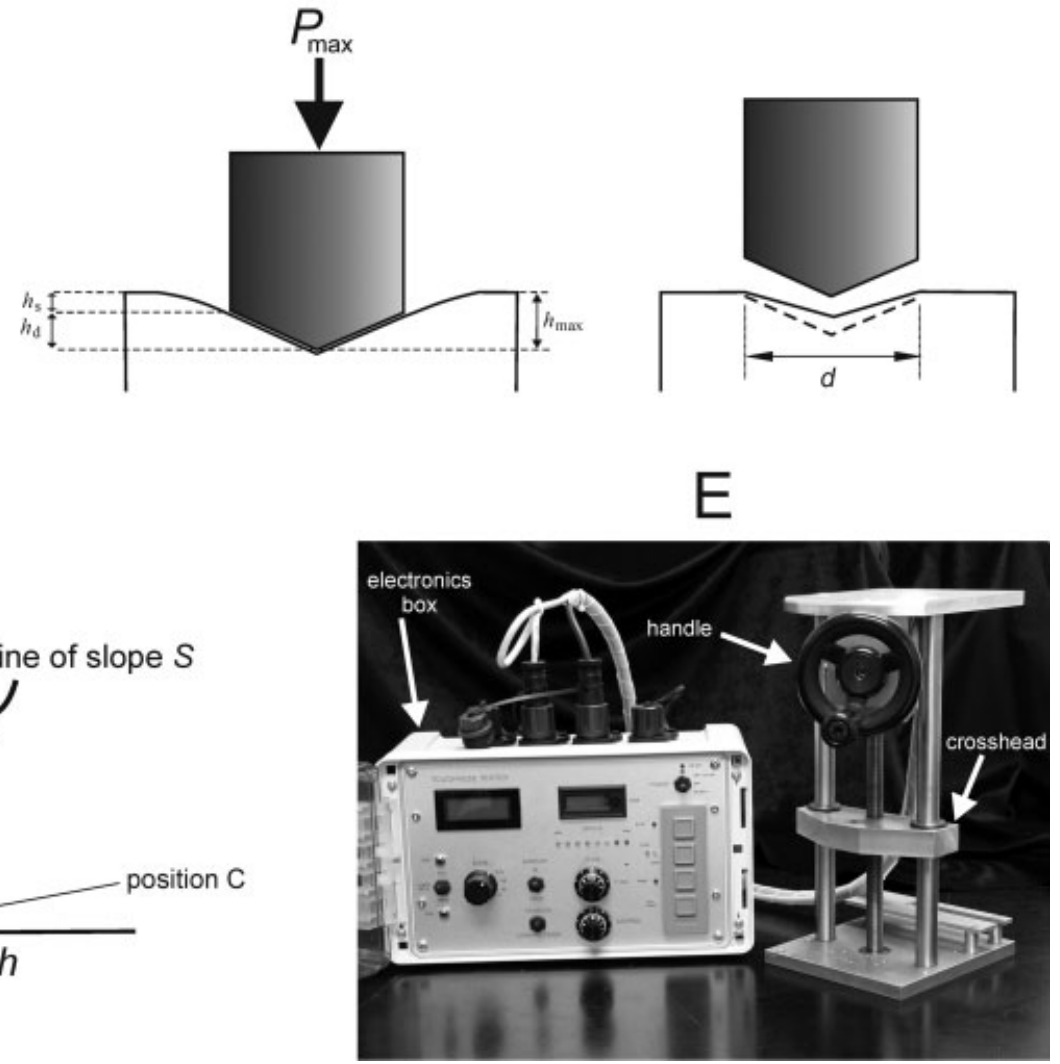

Fig. 1. The principle of depth-sensing indentation tests on an ideal elastic-plastic solid. In A, a pyramidal indenter formed on the end of a cylindrical rod of diameter $d$ is shown in cross section. In $\mathbf{B}$, the indenter has been sunk to full depth into a flat (food) material surface aligned normal to the long axis of the cylinder: it would never be inserted to that depth in practice. Elastic deformation alongside the indenter causes a sinking of the surface at the indenter margin to a depth, $h_{\mathrm{s}}$. The actual contact surface with the indenter only extends to a depth $h_{\mathrm{d}}$, considerably less than the actual displacement of the indenter, which is $h_{\max }$ at full load, $P_{\max }$. In $\mathbf{C}$, after unloading, the remaining permanent indentation still has a surface width $d$, but is shallower and does not fit the indenter shape (dashed line) because of elastic recoil under the indenter tip. In $\mathbf{D}$, the positions of the indenter in A-C are shown on a load-displacement chart. Loading has a curvilinear form because the area of contact increases continuously as the indenter is pushed further into the material. On unloading, the force $P$ does not immediately drop to zero because the material under the indenter tip is still deforming elastically and thus pushes against it as it retreats. The curvilinear form of the unloading curve reflects indenter shape (Oliver and Pharr, 2004). Calculations of $h_{\mathrm{s}}$ involve finding the slope $S$ of the load-displacement at initial unloading. E shows the basic design of the Darvell field tester. A mechanical frame houses a crosshead moved by a handle. Both displacement and force information are transferred to an electronics box, which then transfers signal to a real-time computer display. The indenter, which would be positioned below the crosshead, is wound down onto a specimen resting on the tester base.

wall orthogonal to the top surface was created by similar polishing. Where necessary, specimens were secured to the test stage under the indenter with double-sided sticky tape or with a clamp to stabilize them.

\section{Correction for machine compliance}

The reason for the often relatively huge size of testing machines in mechanical engineering laboratories is to make the machine as stiff as possible, since the aim is to deform the specimen and not the machine itself. However, even for the stiffest of machines, its compliance needs to be corrected for. Calibration in this sense was achieved by replacing the indenter with a flat aluminum block and driving the crosshead down extremely carefully so that this bore on the specimen stage. With a large area of contact, this measures the overall compliance of a tester system (van Vliet et al., 2004). The machine deflection was recorded in this way at each $1 \mathrm{~N}$ interval up to full-scale. These data were then compiled into a look-up table on a computer program for subtraction from the measured deformation automatically during each test run for hardness-modulus tests only.

\section{Hardness-modulus tests}

During testing, the crosshead was first wound down until the indenter was a few micrometers away from contact. With the computer program then started, indentations could be made up to $1 \mathrm{~mm}$ in maximum depth by slowly and regularly winding the crosshead into the specimen at speeds of between 5 and $20 \mathrm{~mm} \mathrm{~min}^{-1}$. Depths of several hundred microns or more were required to minimize the increased compliance caused by the tape, $\sim 50 \mu \mathrm{m}$ in thickness, and inaccuracies of displacement due to backlash in the screw threads. A real- 
TABLE 1. Results of hardness-modulus macro-indentation experiments

\begin{tabular}{|c|c|c|c|c|}
\hline Specimens & $\begin{array}{l}\text { Number } \\
\text { of tests }\end{array}$ & $\begin{array}{l}\text { Indentation } \\
\text { hardness/ } \\
\mathrm{MPa} \text { (s.d) }\end{array}$ & $\begin{array}{l}\text { Reduced } \\
\text { elastic } \\
\text { modulus/ } \\
\text { GPa (s.d.) }\end{array}$ & Other values for comparison \\
\hline \multicolumn{5}{|l|}{ Seed shells } \\
\hline $\begin{array}{l}\text { Scheelea sp. (fam. Arecaceae) Barro } \\
\text { Colorado, Panama }\end{array}$ & 8 & $271.5(74.7)$ & $3.80(0.99)$ & $\begin{array}{l}\text { Modulus: Cocos nucifera } 2.9-4.9 \mathrm{GPa} \\
\text { (Vincent, 1990) }\end{array}$ \\
\hline Orbignya sp. (fam. Arecaceae) Piuai, Brazil & 19 & $148.6(29.2)$ & $1.33(0.21)$ & \\
\hline Astrocaryum sp. (fam. Arecaceae) Piuai, Brazil & 19 & $197.3(31.8)$ & $1.66(0.15)$ & \\
\hline $\begin{array}{l}\text { Elaeis guineensis (fam. Arecaceae) Oil palm } \\
\text { Missouri Botanical Gardens }\end{array}$ & 3 & $126.3(20.6)$ & $2.46(1.04)$ & \\
\hline $\begin{array}{l}\text { Macadamia ternifolia (fam. Arecaceae) } \\
\text { commercial supplier: Australia }\end{array}$ & 5 & $162.2(107.8)$ & $2.59(1.42)$ & $\begin{array}{l}\text { Modulus: 2-6 GPa (Jennings and } \\
\text { Macmillian, 1986); 4.8 GPa (Wang } \\
\text { and Mai, 1994) Hardness: } 180 \mathrm{MPa} \\
\text { (Jennings and Macmillan, 1986) }\end{array}$ \\
\hline \multicolumn{5}{|l|}{ Seed kernels } \\
\hline Almond & 6 & $2.52(0.54)$ & $0.0576(0.02)$ & \\
\hline Hazelnut & 5 & $7.18(4.36)$ & $0.194(0.02)$ & \\
\hline Brazil nut & 6 & $7.13(2.54)$ & $0.198(0.076)$ & $\begin{array}{l}\text { Modulus: } 0.034 \mathrm{GPa} \text { (Agrawal and } \\
\text { Lucas, 2003) }\end{array}$ \\
\hline Macadamia & 5 & $4.90(0.87)$ & $135.0(0.046)$ & $\begin{array}{l}\text { Modulus: } 0.032 \mathrm{GPa} \text { (Agrawal and } \\
\text { Lucas, 2003; 0.045 Wang and Mai, } \\
\text { 1994) }\end{array}$ \\
\hline \multicolumn{5}{|l|}{ Underground Storage organs (vegetables) } \\
\hline Raw white potato & 5 & $0.189(0.012)$ & $0.00412(0.0018)$ & $\begin{array}{l}\text { (Dynamic storage) Modulus: } 0.003 \\
\text { GPa (Dejmek and Miyawaki, 2002) }\end{array}$ \\
\hline Raw carrot & 4 & $1.3(0.71)$ & $0.018(0.007)$ & $\begin{array}{l}\text { Modulus: } 0.0046 \mathrm{GPa} \text { (Lucas, 1980); } \\
\text { 0.0014 GPa (Thiel and Donald, } \\
\text { 1998) }\end{array}$ \\
\hline \multicolumn{5}{|r|}{$1530)$} \\
\hline Polytetra-fluoroethylene (Teflon) & 15 & $41.3(10.25)$ & $0.65(0.10)$ & $\begin{array}{l}\text { Modulus: } 1.46 \mathrm{GPa} \text { (vibration); } 0.50 \\
\text { GPa (compressive modulus-Anon, } \\
\text { 2008) Hardness: } 50-65 \mathrm{MPa} \\
\text { (Kodintseva et al., 2006) }\end{array}$ \\
\hline Polycarbonate (Makrolon GP) & 6 & $275.9(68.3)$ & $1.63(0.18)$ & $\begin{array}{l}\text { Modulus: } 2.35 \mathrm{GPa} \text { (vibration); } 2.38 \\
\text { GPa (Bayer datasheet); } 6.8 \mathrm{GPa} \\
\text { (Oyen and Cook, 2003) Hardness: } \\
260 \mathrm{MPa} \text { (Oyen and Cook, 2003); }\end{array}$ \\
\hline Expanded polystyrene (Styrofoam) & 5 & $0.398(0.034)$ & $0.0084(0.0017)$ & Modulus: $0.0092 \mathrm{GPa}$ (vibration) \\
\hline Polymethyl methacrylate & 2 & $324.2(185.1)$ & $4.49(0.55)$ & $\begin{array}{l}\text { Modulus: } 5.37 \mathrm{GPa} \text { (vibration); } 8.6 \\
\text { GPa (Oyen and Cook, 2003) } \\
\text { Hardness: } 390 \mathrm{MPa} \text { (Oyen and } \\
\text { Cook, 2003) }\end{array}$ \\
\hline
\end{tabular}

time chart of force versus displacement was provided on the computer screen. After loading to the desired depth or force, the crosshead direction was abruptly reversed (without dwelling at maximum load) and the wheel turned at approximately the same speed until the indenter returned to its original out-of-contact position. The form of the resulting graph is shown in Figure 1D.

The area of an indentation is usually measured after unloading by optical means. A significant advance in nanolevel testing has been the employment of a theoretical analysis by Sneddon (1965) that predicts how a material behaves under an indenter during both loading and unloading (Oliver and Pharr, 1992, 2004). This allows the estimation of both hardness (during loading) and the elastic modulus (during unloading) without direct measurement of contact area. The most important point is that an indenter does not have a completely local effect, tending to drag material down on either side as it driven into the material (Fig. 1A,B). Thus, the depth to which an indenter is apparently inserted into a material generally exceeds the actual penetration measured from the (displaced) surface (Oliver and Pharr, 1992). The following shows how analysis usually associated with nanoindentation can be employed in a macro-test.
In an ideal elastic-plastic solid, one that transitions instantly at a yield point from elastic to plastic behavior, if a force $P$ produces a permanent indentation of area $A_{\mathrm{p}}$, this area being that projected in the plane of the specimen surface, then the hardness is given (Tabor, 1951) by the following:

$$
H=P / A_{\mathrm{p}}
$$

The result is not a material property in itself, but an indirect measurement of the plastic deformation that a solid is unable to resist once its yield stress is reached. For most materials, $H=c Y$, where $Y$ is the yield stress and $c$ is a coefficient with a value in the range 1-3 (Tabor, 1951; Wilsea et al., 1975). The higher value is typical of fully dense materials such as metals, whereas the lowest values apply to materials that collapse inwards, as is true of cellular plant tissues and otherwise fully dense materials that have been "foamed" (Gibson and Ashby, 1999).

The amount of sink-in (Fig. 1B) needs to be deducted from the total depth of indenter movement. With depth in general denoted by $h$, the sink-in depth is given (Oliver and Pharr, 2004) by the following: 
TABLE 2. Results of chipping macro-indentation experiments

\begin{tabular}{lccc}
\hline \multicolumn{1}{c}{ Specimens } & Number of tests & Toughness $/ \mathrm{MPa} \mathrm{m}^{1 / 2}(\mathrm{s.d})$ & Other values for comparison \\
\hline Seed shells & & & \\
Orbignya sp. & 16 & $1.93(0.7)$ & Cocos nucifera 2.65 (Vincent, 1990) \\
Scheelea sp. & 8 & $2.77(1.1)$ & (Wang and Mai, 1994) \\
Astrocaryum sp. & 10 & $2.60(0.8)$ & 0.6 (Lawn, 1993) \\
Macadamia ternifolia & 5 & $1.13(0.12)$ & \\
Standard ceramic & 15 & $0.58(0.05)$ & \\
$\quad$ Sodalime glass & &
\end{tabular}

$$
h_{\mathrm{s}}=h_{\max }=\varepsilon\left(P_{\max } / S\right)
$$

where, $h_{\max }$ is the total displacement of the indenter at the maximum force $P_{\max }, S$ is the slope of the force-displacement curve on initial unloading (Fig. 1C,D), and $\varepsilon$ is a coefficient called the "effective indenter shape." The actual depth of the indentation with material in contact (Oliver and Pharr, 1992) is as follows:

$$
h_{\mathrm{d}}=h_{\max }-h_{\mathrm{s}}
$$

The area of contact $A_{\mathrm{p}}$ can then be estimated directly from the indenter geometry, and the indentation hardness given directly by Eq. (1), with the distinction that the area is not measured after unloading. Also, from Oliver and Pharr (1992, 2004, the estimate of the elastic modulus $E$ is then given by:

$$
E=2 \beta A_{\mathrm{p}}^{1 / 2} / \pi^{1 / 2} S
$$

with $\beta$ being another function of indenter shape. The projected area for a Vickers pyramid is related to depth by $A_{\mathrm{p}}=25.4 h_{\mathrm{d}}$. According to Tanaka et al. (2004), the coefficient $\varepsilon \approx 1$, meaning that the Vickers indenter behaves in many ways as though it was a flat punch, and $\beta=1.153$. The initial unloading stiffness $S$ could be determined by linear regression of force on displacement for the upper part of the unloading curve after subtraction of machine compliance (Fig. 1D).

The resulting modulus value is often called the reduced elastic modulus because it is a composite of the properties of both indenter and (food) specimen. However, compensation for the indenter modulus of elasticity makes a negligible difference to values in this study because of the much lower modulus values for the food objects compared with that of stainless steel (210 GPa) or tungsten carbide $(\sim 700 \mathrm{GPa})$. Even for the stiffest object tested here, the error in not performing this final step would be $<4 \%$.

\section{Chipping tests}

The toughness $T$ of sufficiently hard materials can be obtained from tests whereby chips are removed from the edge of specimens at the junction of two orthogonal surfaces (Chai and Lawn, 2007). A major caveat is that the material has to be sufficiently brittle for catastrophic failure and also sufficiently homogeneous for chip morphology not to be dictated by favored planes of fracture within the material. With the indenter directed normal to one of these surfaces, and the indenter tip lying a distance $a$ from the interface intersection of the surfaces, the toughness $T$ is readily obtained from the maximum force $P_{\max }$ at chip removal (Chai and Lawn, 2007), being

$$
T=P_{\max } / 9.3 a^{1.5}
$$

To both align the indenter and to view the chipping process, a USB digital portable microscope (Veho VMS-001, Eastleigh, Hants, UK) was focused on the stage, images being viewed in real time. The maximum force was given directly on the computer screen, and easily observed because of the abrupt load drop when a chip is removed. Thus, the only dimension required by direct measurement in this entire study is that of $a$, which was achieved here using calipers under the microscope. The resulting toughness estimate has units of $\mathrm{MPa} \mathrm{m}^{1 / 2}$.

\section{RESULTS Hardness-modulus}

Results are given in Table 1 . The average estimates for the elastic modulus of the polymers were slightly lower than those given by vibration testing (as expected), but similar to those obtained from literature sources (static values). There appeared to be no large discrepancies, but the standard deviations were often large. Hardness estimates also showed large scatter, but the results seem entirely reasonable in relation to available literature values. The moduli for the seed shells were similar to those for polymers and to literature values. However, the moduli for the seed kernels and the two root vegetables were somewhat overestimated compared with data from other tests, often being more than double those from direct compression tests (Table 1).

\section{Toughness}

Examples of chips in sodalime glass and macadamia shells are shown in Figure 2. When the peak force for chipping sodalime glass was plotted against $9.3 a^{1.5}$, for various $a$, a straight line resulted (Fig. 4), giving a slope of $0.58 \mathrm{MPa} \mathrm{m}^{1 / 2}$ (Fig. 4). Data for the toughness of glass and four nutshells are given in Table 2. Often, chip size was limited by shell thickness (e.g., for macadamia shells, which were only $2 \mathrm{~mm}$ thick); but for feasible values of $a$, toughness did not vary with either $P_{\max }$ or $a$, and chips generally had similar shapes to those of ideal brittle materials (cf. Fig. 3A-B).

\section{DISCUSSION Evaluation of test results}

The main assumption of depth-sensing indentation experiments is that the material behaves like an ideal, linearly elastic-plastic solid (Oliver and Pharr, 1992, 2004). However, no real solid, not even a ceramic, 

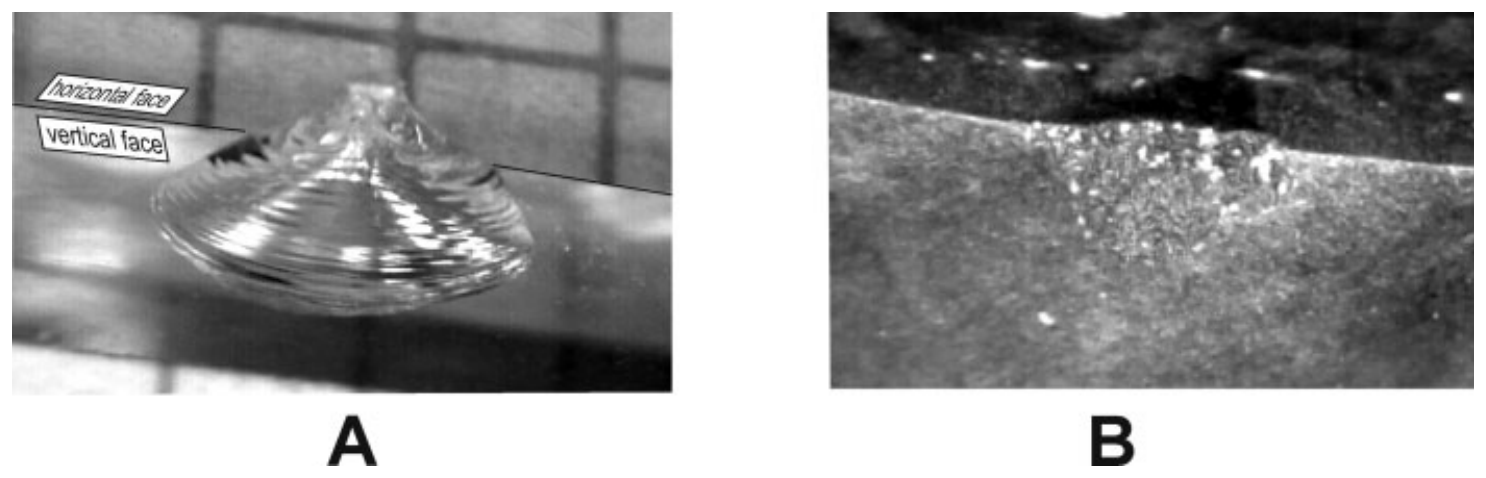

Fig. 2. Chips produced in sodalime glass $(a=0.64 \mathrm{~mm})$ and the "equatorial region" of macadamia nutshell $(a=0.42 \mathrm{~mm})$, as imaged by the digital microscope.

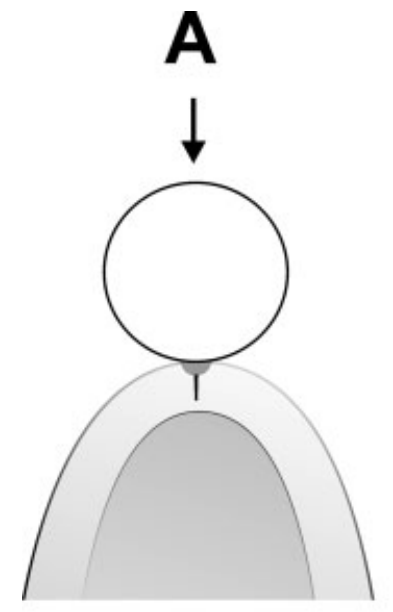

median crack

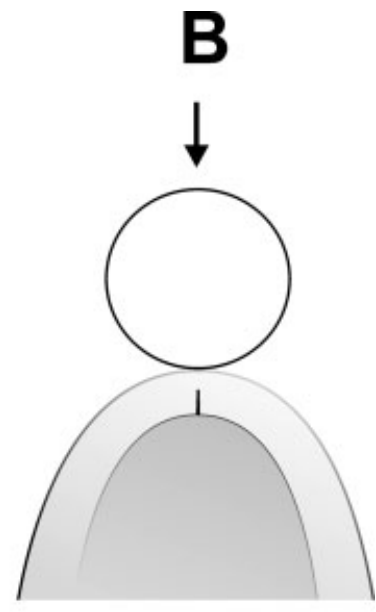

radial crack

Fig. 3. A schematic diagram of the consequences of the contact of a tooth (enamel shaded light; dentine dark) with a spherical "hard" food particle, pressed together in the direction of the arrow. In $\mathbf{A}$, if the indentation hardness of the food particle exceeds $40 \%$ of that of enamel, the enamel may yield beneath the indenter (shown as dark semicircular zone) at low forces. A median crack may project vertically from it. With less hard food particles, there are two other damage possibilities. In B, a radial crack may initiate in the enamel from the enamel-dentine junction below the contact point (indicated by a large dot).

behaves exactly like this, and polymers display a distinct viscous response even at low strains (Oyen and Cook, 2003). Fluid-filled cellular plant tissues can have a very pronounced time-dependent response with considerable deviation from linear stress-strain behavior (Warner et al., 2000). Yet, very soft nonlinear biomaterials like gels can still be tested by indentation (Ross and Scanlon, 2007), even though full interpretation of the results requires quantification of time-dependent constants (Goh et al., 2004). Despite these limitations, both the properties of polymers and those of seed shells in Table 1 are in reasonable agreement with the literature and our own nonindentation estimates. There was less success for the softer materials and it is clear that indentation tests as applied here are insufficient. The real value of this study

though lies more in its applicability to seed shells and the like because, as stated in the "Introduction," these are otherwise very difficult to test in the field. Thus, we believe that numbers for hardness, modulus, and probably toughness can be obtained for fallback objects from field tests. The values for the seed shells in Table 1 are in the low GigaPascal range, and as such are two orders of magnitude higher than those given in the review of orangutan and chimpanzee foods given by Vogel et al. (2008), suggesting the necessity for techniques such as these to examine the properties of, e.g., dry fruits and seed shells. The hardness values are low even compared with dentine (650 MPaWaters, 1980) and very low compared with enamel ( 3,000-6,000 MPa Cuy et al., 2002).

\section{The potential of hard fallback foods to damage teeth}

Tooth crowns are vulnerable to several types of fracture. Contact with a hard particle can cause yielding (i.e., plastic deformation) of the enamel (Lawn et al., in press), just as in a hardness test where the enamel is the specimen. Yielding though is only a contributory factor to tooth wear and will not cause catastrophic failure of the tooth. However, if enamel yields before failing, then a median crack can grow directly from the undersurface of the plastically deforming zone down through the enamel (Lawn and Evans, 1977; Fig. 3A). Enamel can also crack at the enamel-dentine junction, with the crack climbing upwards toward the point of contact with the food (Fig. 3B). This latter type of fracture is called a radial crack. The crown can also fracture very low down near the cement-enamel junction. Such margin cracking is commonly encountered in the modern human dentition (Grippo, 1991), but is discussed elsewhere (Lawn et al., 2009).

The important question to be addressed here is which of these types of damage may be resisted by thick enamel. Yielding is the name given to the switch in behavior of a solid under load from elastic deformation to permanent (plastic) deformation beyond a particular value of the stress. It is yielding that leads to marks, like the pits or scratches typical of dental microwear, being left on a surface after the load is removed. The relative hardness of two contacting bodies under load is important in establishing which of these objects will yield. Yielding is a general precursor to wear (Lucas et al., 2008), which may be an important aspect of anatomical 


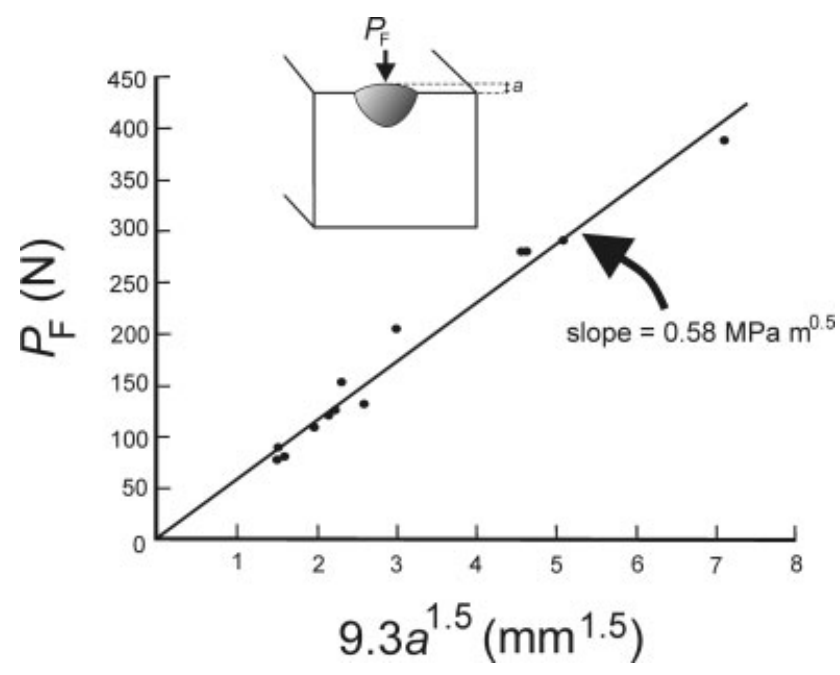

Fig. 4. The graph shows chipping results for sodalime glass, plotting the peak force $P_{\mathrm{F}}$ against $9.3 a^{1.5}$. The gradient of the graph, obtained by least-squares regression, gives the toughness $T$. The linearity of the data for different chip sizes attests to the scale-invariance of the relationship.

specializations in relation to fallback foods (Lambert et al., 2004; Marshall and Wrangham, 2007). Generally, if the softer object is less than $40 \%$ of the hardness of a harder one, then the harder one will not yield at all (Atkins and Felbeck, 1974; Atkins, 1982). In such a situation, the critical load at yield for the softer solid is given (Rhee et al., 2001) by the following:

$$
P_{\mathrm{Y}}=0.85 H(H / E)^{2} r^{2}
$$

where $r$ is the effective radius of contact between the contacting bodies, and $E$ and $H$ are the modulus and hardness of the softer object, respectively (Rhee et al., 2001). It can immediately be noted that yielding has no dependence on the thickness of the enamel. However, this is probably not relevant anyway because none of the estimated hardness values of the seed shells exceeds 300 $\mathrm{MPa}$. This value should be compared with average values of 3,600 MPa for enamel and $650 \mathrm{MPa}$ for primary dentine (Braden, 1976; Waters, 1980; Cuy et al., 2002; Lucas, 2004). Clearly, these food coverings have only $\sim 10 \%$ of the hardness of enamel and will not mark it, as was established experimentally by Peters (1982). The hardness values are closer to those of primary dentine, and even more so with secondary dentine, which can have values as low as $300 \mathrm{MPa}$ (Baker et al., 1959; Lucas, 2004). Thus, dentine may be damaged by seed shells, but not enamel. Seed shells themselves are likely to yield. As an estimate of the magnitude of the force required to produce this, values of $H=200 \mathrm{MPa}$ and $E=3 \mathrm{GPa}$ (Table 1) can be inserted in Eq. (5), together with $r=20 \mathrm{~mm}$ as a typical size of a fallback food object (Table 3). The result is yielding at around $300 \mathrm{~N}$.

\section{Use of the data to calculate the force to fracture fallback foods}

Seeds have many parallels to teeth. They are often bilayered, being covered with a thin, stiff, and hard shell

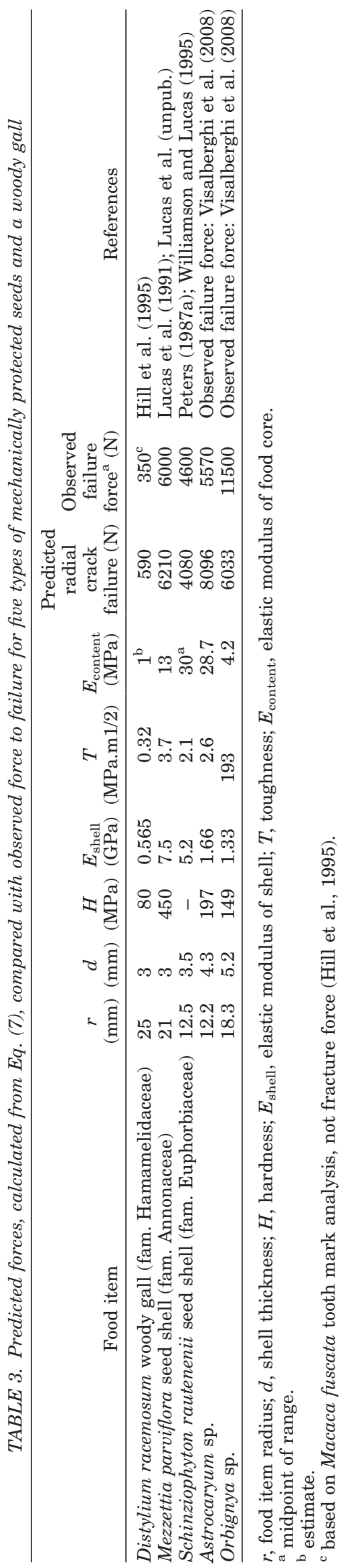


with a fibrous structure that can mimic enamel (Lucas et al., 2008). Margin cracks are not relevant because shells are encapsulating structures rather than crowns, so instead median and radial cracks are the major threat to their integrity. Wang and Mai (1994) suggested that the shells of macadamia (Macadamia ternifolia) nuts often fail by radial (i.e., deep) cracks. Lucas et al. (1994) found for both macadamia nuts and Mezzettia parviflora seeds eaten by orangutans in Borneo that loading them either with flat plates or tooth row replicas has little influence on the force at which the seed fails. Lawn and Lee (in press) explain this by showing that the condition for catastrophic failure is similar for both median and radial cracks as they spread around the shell. The force for propagation of both of these types of crack is given by the following:

$$
P_{\mathrm{F}}=B_{\mathrm{F}} T d^{1.5} / \log \left(E_{\text {shell }} / E_{\text {content }}\right)
$$

where, $T$ is the toughness, $d$ is the shell thickness, $E_{\text {shell }}$ is the shell modulus, $E_{\text {content }}$ is the modulus of the encapsulated tissue, and $B_{\mathrm{F}}=13.5+2.1(\mathrm{r} / \mathrm{d})$ (Rhee et al., 2001; Rudas et al., 2005; Lawn and Lee, in press). It can be noted in Eq. (7) that, the force will generally be raised by increasing $d$, i.e., by thickening the outer shell. Also, because of the inclusion of the radius of curvature in the coefficient, a shell of higher radius will have greater resistance to failure. Since seeds yield, the equation is relevant both to the propagation of median and radial cracks. Although enamel is unlikely to yield, it is still vulnerable to radial cracking and thus both enamel thickness and cuspal radius will be important in preventing tooth fracture.

Although toughness estimates were not obtained in this study, they could be incorporated into future studies if crack lengths can be obtained and measured following indentation. The importance of this is indicated in Table 3, which uses Eq. (6) to predict the bite force from literature estimates of the properties of three types of fallback food, two from primate studies, and one from the human literature (Peters, 1987b). For each of these objects, the predicted failure force from radial cracking lies fairly close to that predicted by Eq. (6) for $P_{\mathrm{F}}$.

\section{Applicability of the analysis in a broader context}

It is clear that hard foods in primate diets are probably much less hard than enamel, but can approach that of dentine. This needs documenting. If a hardness disparity between enamel and dentine were not present, then unless ingested particle sizes were really large, the enamel would yield at far below the forces at which the food objects in Table 3 fail (Lucas et al., 2008; Lawn et al., 2009; Constantino et al., submitted). This puts an evolutionary premium on enamel hardness and stiffness to far exceed that of foods and their coverings. Once cracking has started, then enamel thickness comes into play as a protective mechanism: the thicker the enamel, the higher would be the forces that cause catastrophic cracking. Further, since the coefficient $B_{\mathrm{F}}$ increases with the radius of curvature of a cusp, blunter cusps crack at higher loads than sharper ones. Once enamel thins, the cusp becomes vulnerable, and once dentine is exposed, the latter would wear rapidly because it would yield against seed shell and at lower force. One functional aspect of a thick enamel cap is to delay such dentinal exposure.

Bite forces and the arrangement of jaw muscles and skeleton to achieve these efficiently are a traditional concern of researchers in mammalian jaw mechanics (e.g., Crompton, 1963; Bramble, 1978; Greaves, 1978; Walker, 1978; Hylander, 1978, 1985; Spencer, 1998). Most often, the bite is assumed to be a point load-the circumstances likely when hard (fallback) foods are eaten. There do not appear to be any previous estimates of the actual forces needed to destroy a food object that could inform such analyses, so the only actual data generally comes from bite-force gauges. Our point here is that many researchers have used gauges with a very high modulus and hardness. In studies on humans, a classic form is a tuning fork (Carlsson, 1974). A surface liner is often used, but if this is thin, then it will do little to spread the force before the properties of the underlying metal prevail. A bite-force gauge made out of stainless steel would have $H>2,000 \mathrm{MPa}$ and $E=210 \mathrm{GPa}$ (Atkins and Mai, 1985). In a sense, such a gauge is a mimick of a fallback food, but differing in that it is very much harder. Such steel is almost certain to cause yielding in enamel. The yield force $P_{\mathrm{Y}}$ can be predicted from Eq. (6), and though its actual value depends on the radius of contact, it is likely to be very much lower than the $\sim 800$ $\mathrm{N}$ often quoted in studies of maximum bite force in young human adults (Braun et al., 1995; Miyawaki et al., 2005). If a human subject can sense local yielding in enamel, a possibility that is strongly supported by the studies of Paphangkorakit and Osborn (1998a, 2000), then measurements might not actually pick up the maximum force that subjects could generate because the subject would desist at this point. The influence of gauge rigidity is sometimes mentioned (Braun et al., 1995), but Paphangkorakit and Osborn (1998b) have actually shown that an "elastic" design of gauge can significantly increase the bite forces that human subjects are prepared to generate.

\section{ACKNOWLEDGMENTS}

The support of GWU Vice-President Lehman is gratefully acknowledged.

\section{LITERATURE CITED}

Agrawal KR, Lucas PW. 2003. The mechanics of the first bite. Proc Biol Sci 270:1277-1282.

Anon. 2008. Fluoropolymer comparison-typical properties. Dupont. Available at: www2.dupont.com/Teflon_Industrial/en_ US/tech_info/techinfo_compare.html

Anstis GR, Chantikul P, Marshall DB, Lawn BR. 1981. A critical evaluation of indentation techniques for measuring fracture toughness. I. Direct crack measurements. J Am Ceram Soc 64:533-538.

Atkins AG. 1982. Topics in indentation hardness. Met Sci 16:127-137.

Atkins AG, Felbeck DK. 1974. Applying mutual indentation hardness phenomena to service failures. Met Eng Q 14:55-61.

Atkins AG, Mai Y-W. 1985. Elastic and plastic fracture. Chichester: Ellis Horwood.

Baker G, Jones LHP, Wardrop ID. 1959. Cause of wear in sheeps' teeth. Nature 184:1583-1584.

Braden M. 1976. Biophysics of the tooth. In: Kawamura Y, editor. Frontiers of oral physiology, Vol. 2. Basel: Karger. p 137. 
Bramble DM. 1978. Origin of the mammalian feeding complex: models and mechanisms. Paleobiology 4:271-301.

Braun S, Bantleon H-P, Hnat WP, Freudenthaler J-W, Marcotte MR, Johnson BE. 1995. A study of bite force. I. Relationship to various physical parameters. Angle Orthod 65: 367-372.

Carlsson GE. 1974. Bite force and chewing efficiency. In: Kawamura Y, editor. Frontiers of oral physiology, Vol. 1. Basel: Karger. p 265-292.

Chai H, Lawn BR. 2007. A universal relation for edge chipping from sharp contacts in brittle materials: a simple means of toughness evaluation. Acta Mater 55:2555-2561.

Crompton AW. 1963. On the lower jaw of Diarthrognathus and the evolution of the mammalian lower jaw. Proc Zool Soc Lond 140:697-753.

Cuy JL, Mann AB, Livi KJ, Teaford MF, Weihs TP. 2002. Nanoindentation mapping of the mechanical properties of human molar enamel. Arch Oral Biol 47:281-291.

Darvell BW, Lee PKD, Yuen TDB, Lucas PW. 1996. A portable fracture toughness tester for biological materials. Meas Sci Technol 7:954-962.

Dejmek P, Miyawaki O. 2002. Relationship between the electrical and rheological properties of potato tuber tissue after various forms of processing. Biosci Biotechnol Biochem 66:1218-1223.

Fratzl P. 2007. Biomimetic materials research: what can we really learn from nature's structural materials? J R Soc Interface 4:637-642.

Gibson LJ, Ashby MF. 1999. Cellular solids: structure and properties, 2nd ed. Cambridge: Cambridge University Press.

Goh SM, Charalambides MN, Williams JG. 2004. Characterisation of nonlinear viscoelastic foods by the indentation technique. Rheol Acta 44:47-54.

Greaves WS. 1978. The jaw-lever system in ungulates: a new model. J Zool 184:271-285.

Grippo JO. 1991. Abfraction: a new classification of hard tissue lesions of teeth. J Esthet Restor Dent 3:14-18.

He L, Swain MV. 2007. Contact induced deformation of enamel. Appl Phys Lett 90:171916, 1-3.

Hill DA, Lucas PW, Cheng PY. 1995. Bite forces used by Japanese macaques (Macaca fuscata yakui) on Yakushima Island, Japan to open aphid-induced galls on Distylium racemosum (Hamamelidaceae). J Zool 237:57-63.

Hylander WL. 1978. Incisal bite force direction in humans and the functional significance of mammalian mandibular translation. Am J Phys Anthropol 48:1-8.

Hylander WL. 1985. Mandibular function and biomechanical stress and scaling. Am Zool 25:315-330.

Jennings JS, Macmillan NH. 1986. A tough nut to crack. J Mater Sci 21:1517-1524.

Kinzey WG, Norconk MA. 1990. Hardness as a basis of fruit choice in two sympatric primates. Am J Phys Anthropol 81:515 .

Kinzey WG, Norconk MA. 1993. Physical and chemical properties of fruit and seeds eaten by Pithecia and Chiropotes in Surinam and Venezuela. Int J Primatol 14:207227.

Kodintseva TA, Kaskarov AM, and Kaloshin VA. 2006. Hardness evaluation of polytetrafluoroethylene products. 9th European Conference on Non-Destructive Testing, Berlin, Germany, poster 111 .

Lambert JE, Chapman CA, Wrangham RW, Conklin-Brittain NL. 2004. Hardness of cercopithecine foods: implications for the critical function of enamel thickness in exploiting fallback foods. Am J Phys Anthropol 125:363-368.

Lawn BR. 1993. Fracture of brittle solids, 2nd ed. Cambridge: Cambridge University Press.

Lawn BR, Evans AG. 1977. A model for crack initiation in elastic/plastic indentation fields. J Mater Sci 12:21952199.

Lawn BR, Howes VR. 1981. Elastic recovery at hardness indentations. J Mater Sci 16:2745-2752.

Lawn BR, Lee JJ, Constantino PJ, Lucas PW. 2009. Predicting failure in mammalian enamel. J Mech Behav Biomed Mat 2:33-42.
Lawn BR, Lee JJ-W. in press. Analysis of fracture and deformation in teeth subjected to occlusal loading. Acta Biomat.

Lawn BR, Lee JJ-W, Constantino PJ, Lucas PW. 2008. Predicting failure in mammalian enamel. $J$ Mech Behav Biomed Mater 2:33-42.

Lucas PW. 1980. Adaptation and form of the mammalian dentition with special reference to primates and the evolution of man, Ph.D. thesis. University of London: London.

Lucas PW. 2004. Dental functional morphology: how teeth work. Cambridge: Cambridge University Press.

Lucas PW, Constantino P, Wood BA, Lawn BR. 2008. Dental enamel as a dietary indicator in mammals. BioEssays 30:374285.

Lucas PW, Lowrey TK, Pereira B, Sarafis V, Kuhn W. 1991. The ecology of Mezzettia leptopoda Hk. f. et Thoms. (Annonaceae) seeds as viewed from a mechanical perspective. Funct Ecol 5:345-353.

Lucas PW, Peters CR, Arrandale S. 1994. Seed-breaking forces exerted by orang-utans with their teeth in captivity and a new technique for estimating forces produced in the wild. Am J Phys Anthropol 94:365-378.

Lucas PW, Prinz JF, Agrawal KR, Bruce IM. 2002. Food physics and oral physiology. Food Qual Prefer 13:203-213.

Lucas PW, Turner IM, Dominy NJ, Yamashita N. 2000. Mechanical defences to herbivory. Ann Bot 86:913-920.

Marshall AJ, Wrangham RW. 2007. Evolutionary consequences of fallback foods. Int J Primatol 28:1219-1235.

Miyawaki S, Araki Y, Tanimoto Y, Katayama A, Fujii A, Imai M, Takano-Yamamoto T. 2005. Occlusal force and condylar motion in patients with anterior open bite. J Dent Res 84:133-137.

Oliver WC, Pharr GM. 1992. An improved technique for determining hardness and elastic modulus using load and sensing indentation experiments. J Mater Res 7:15641582 .

Oliver WC, Pharr GM. 2004. Measurement of hardness and elastic modulus by instrumented indentation: advances in understanding and refinements to methodology. J Mater Res 19:3-20.

Oyen ML, Cook RF. 2003. Load-displacement behavior during sharp indentation of viscous-elastic-plastic materials. J Mater Res 18:139-150.

Paphangkorakit J, Osborn JW. 1998a. The effect of normal occlusal forces on fluid movement through human dentine in vitro. Arch Oral Biol 43:1-7.

Paphangkorakit J, Osborn JW. 1998b. Discrimination of hardness by human teeth apparently not involving periodontal receptors. Arch Oral Biol 43:833-839.

Paphangkorakit J, Osborn JW. 2000. The effect of normal occlusal forces on fluid movement through human dentine in vitro. Arch Oral Biol 45:1033-1041.

Peters CR. 1982. Electron-optical microscopic study of incipient dental microdamage from experimental seed and bone crushing. Am J Phys Anthropol 57:283-301.

Peters CR. 1987a. Nut-like oil seeds: food for monkeys, chimpanzees, humans and probably ape-men. Am J Phys Anthropol 73:333-363.

Peters CR. 1987b. Ricinodendron rautanenii (Euphorbiacaeae): Zambezian wild food plant for all seasons. Econ Bot 41:494502.

Rhee Y-W, Kim H-W, Deng Y, Lawn BR. 2001. Contact-induced damage in ceramic coatings on compliant substrates. J Am Ceram Soc 84:1066-1072.

Ross KA, Scanlon MG. 2007. Analysis of the elastic modulus of agar gel by indentation. J Texture Stud 20:1727.

Rudas M, Qasim T, Bush MB, Lawn BR. 2005. Failure of curved brittle layer systems from radial cracking in concentrated surface loading. J Mater Res 20:2812-2819.

Sanson GD, Kerr SA, Gross KA. 2007. Do silica phytoliths really wear mammalian teeth? J Arch Sci 34:526-531.

Sneddon IN. 1965. The relation between load and penetration in the axisymmetric Boussinesq' problem for a punch of arbitrary profile. Int J Sci Eng 3:47-57. 
Spencer M. 1998. Force production in the primate masticatory system: electromyographic tests of biomechanical hypotheses. J Hum Evol 34:25-54.

Tabor D. 1951. Hardness of metals. Oxford: Clarendon.

Tanaka K, Kanari M, Matsui N. 2004. A continuum dislocation model of Vickers indentation on a zirconia. Acta Mater 47:2243-2257.

Thiel BL, Donald AM. 1998. In situ mechanical testing of fully hydrated carrots (Daucus carota) in the environmental SEM. Ann Bot 82:827-833.

van Vliet KJ, Prchlik L, Smith JF. 2004. Direct measurement of indentation frame compliance. J Mater Res 19: 325-331.

Vincent JFV. 1990. Fracture properties of plants. Adv Bot Res 17:235-287.

Vincent JFV, Saunders DEJ, Beyts P. 2002. The use of stress intensity factor to quantify "hardness" and "crunchiness" objectively. J Texture Stud 33:149-159.

Visalberghi E, Sabbatini G, Spagnoletti N, Andrade FRD, Ottoni E, Izar P, Fragaszy D. 2008. Physical properties of palm fruits processed with tools by wild bearded capuchins (Cebus libidinosus). Am J Primatol 70:884-891.

Vogel ER, van Woerden JT, Lucas PW, Utami Atmoko SS, van Schaik CP. 2008. Functional ecology and evolution of hominoid enamel thickness: Pan troglodytes schweinfurthii and Pongo pygmaeus wurmbii. J Hum Evol 55:60-74.

Walker AC. 1978. Functional anatomy of oral tissues: mastication and deglutition. In: Shaw JH, Sweeney EA, Cappuccino CC, Meller SM, editors. Textbook of oral biology. Philapdelphia: WB Saunders.

Wang C-H, Mai Y-W. 1994. Deformation and fracture of macadamia nuts. I. Microstructure and fracture mechanics analysis of nutshell. Int J Fracture 69: 67-85.

Warner M, Thiel BL, Donald AM. 2000. The elasticity and failure of fluid-filled cellular solids: theory and experiment. Proc Natl Acad Sci USA 97:1370-1375.

Waters NE. 1980. Some mechanical and physical properties of teeth. In: Vincent JFV, Currey JD, editors. The mechanical properties of biological materials. Cambridge: Cambridge University Press. p 99-135.

Williamson L, Lucas PW. 1995. The effect of moisture content on the mechanical properties of a seed shell. J Mater Sci 30:162-166.

Wilsea M, Johnson KL, Ashby MF. 1975. Indentation of foamed plastics. Int J Mech Sci 17:457-460.

Wright BW. 2005. Craniodental biomechanics and dietary toughness in the genus Cebus. J Hum Evol 48:473-492. 